\title{
Plitidepsin Under Clinical Trial for COVID-19
}

\author{
Shamail Zia ${ }^{1 *}$, Syed Jawwad $\mathrm{Ali}^{2}$ and Farozaan Shamail ${ }^{1}$ \\ ${ }^{1}$ Department of Dermatology, Zia Medicare Skin Center, Karachi, Pakistan \\ ${ }^{2}$ Department of Pathology, Dow University of Health Sciences, Karachi, Pakistan
}

\section{Respected Editor,}

Our team wants to draw attention to the clinical trial of the drug Plitidepsin for COVID-19 treatment. SARS-CoV-2 has caused a catastrophe worldwide devastatingly of over 208 million confirmed cases and more than 4.4 million deaths reported worldwide as of early September 2021 according to WHO. Despite of being the only approved antiviral drug for the specific treatment of COVID-19 i.e. Remdesivir, has limited efficacy against the virus [1]. Because of very limited options for treatment, scientists have to work hard to find out more treatment options to protect humanity from the next pandemic.

SARS-CoV-2 encounters many proteins for replicating inside the human cell, such proteins can be targeted for clinical trials for a new antiviral drug. One such host protein is Eukaryotic elongation factor-1A (eEF1A) and its inhibitor has come under significant interest for researchers [2]. The Plitidepsin's antiviral activities are mediated through its inhibition of Eukaryotic Elongation Factor 1A (eEF1A) [3]. It has a cytostatic impact on cell proliferation and strongly inhibits nucleocapsid protein expression, thus inhibiting the cytoplasmic replication stage [4]. Plitidepsin isolated from the marine tunicate Aplidium Albicans (Fig. 1).

Plitidepsin has successfully completed a FDA phase II clinical trial for the treatment of COVID-19 by the pharmaceutical company PharmaMar and entered into a phase III with evidence of a safe clinical profile [5]. For the treatment of multiple myeloma Plitidepsin is also registered for Phase 1 clinical trial with bortezomib and dexamethasone [6]. As an antiviral, the company conducted a multicenter, randomized, parallel, open-label study to assess the safety profile, and clinical efficacy with three different Plitidepsin dose level cohorts $(1.5 \mathrm{mg}$ - $2.0 \mathrm{mg}-2.5 \mathrm{mg}$ ), administered over three consecutive days, in patients with COVID-19, who required hospital admission. The patient's viral load was evaluated quantitatively at the beginning of the treatment and on days $4^{\text {th }}, 7^{\text {th }}, 15^{\text {th }}$, and $30^{\text {th }}$. The study has demonstrated a substantial reduction of the viral load in patients between day $4^{\text {th }}$ and $7^{\text {th }}$, the average reduction of the viral load on day $7^{\text {th }}$ was $50 \%$ and on day $15^{\text {th }} 70 \%$. More than $90 \%$ of the patients included in the trial had medium or high viral loads at the start of therapy.

\footnotetext{
*Corresponding author: Shamail Zia, Department of Dermatology, Zia Medicare Skin Center, Karachi, Pakistan; Email: drshamailzia@gmail.com Received: August 21, 2021; Revised: October 14, 2021; Accepted: October 23, 2021 DOI: https://doi.org/10.37184/lnjpc.2707-3521.3.25
}

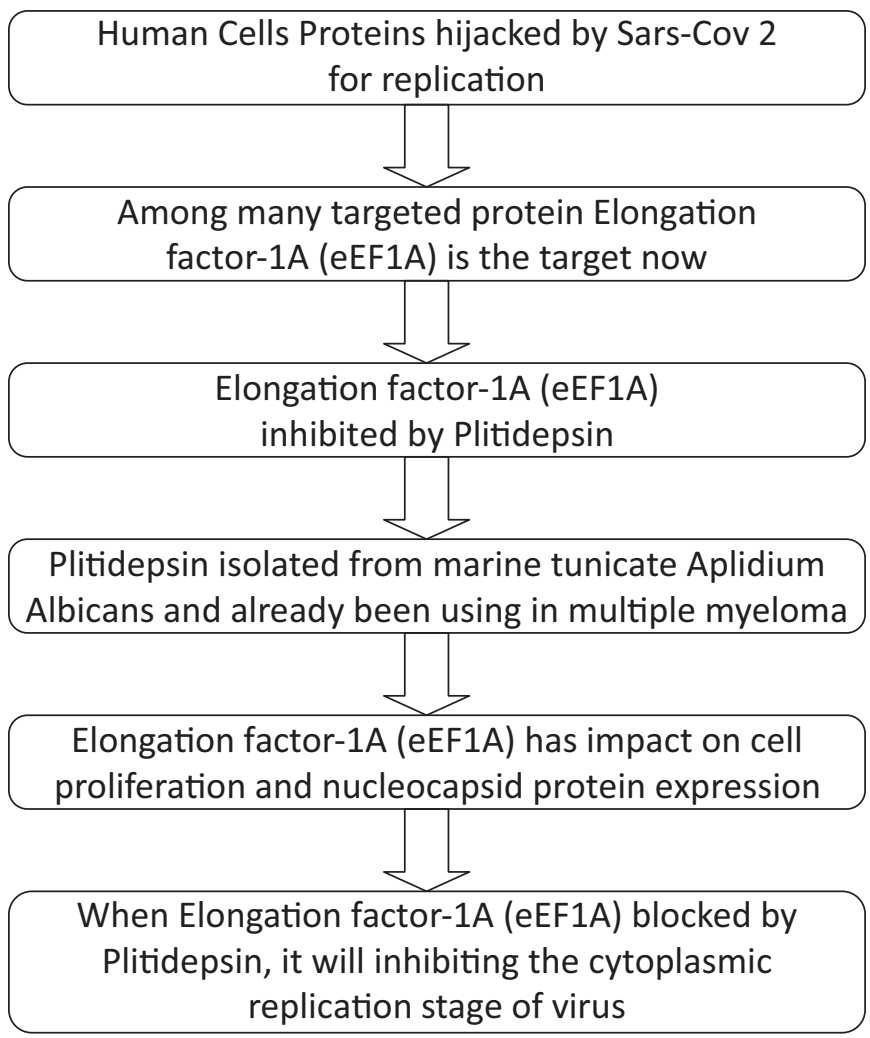

Fig. (1): Diagrammatic view of the process.

Scientists have screened the existing drugs approved in a various types of diseases, to assess how they restrain the SARS-CoV-2-persuaded in-vitro cytopathic effect and viral replication. Seventy two (72) likely antivirals that were previously suggested to impede infection of SARSCoV-2, only $18 \%$ are working above the bar, including fenofibrate, camostat, nelfinavir mesylate hydrate, interferon 2-alpha, interferon-gamma, plitidepsin, novel cathepsin inhibitor and the well-known chloroquine derivatives and remdesivir. Among nanomolar efficacy category Plitidepsin was the only clinically approved drug [7].

We provided this knowledge because we want to draw the attention of researchers and the doctor communities that scientists and pharmaceutical companies are working very hard to discover new treatment regimens against SARS CoV 2. Moreover, the same development is also going from the platform of Terve Innova Company, which is in the primitive stages of trials on the adjunct treatment choices for the treatment of COVID-19. We should be 
proud of all of those people and companies working on these projects. Vaccines are available nowadays but still, a need for Anti-Viral drugs persists as evident from the history e.g. in 1918 (H1N1) viral pandemic, 1968 (H3N2) viral pandemic, and then 2019. We have to search for new options to prevent new pandemic waves [8]. It's time to start investing more money in health care.

\section{CONFLICT OF INTEREST}

The authors declare no conflict of interest.

\section{ACKNOWLEDGEMENTS}

We are thankful for our mentors a) Dr. Naeem Uddin, practicing Dermatologist, Scientist and 5 USPTO Patents Holder Karachi, Pakistan, b) Dr. Atif Ali Hashmi, Department of Pathology Associate Professor Liaquat National Hospital Karachi, Pakistan, c) Dr. Adeel Ahmed, American Board Certified Dermatopathologist, Beckley, West Virginia, United States of America, and d) Dr. Ghassan Tranesh, Assistant Professor University of Arizona College of Medicine, Tucson, Arizona, United States of America, Fazail Zia, Muhammad Ali Khan, Vardah Zia, Syed Minhaj Hussain, Syed Rafay Yaqeen.

\section{REFERENCES}

1. Beigel JH, Tomashek KM, Dodd LE, Mehta AK, Zingman BS, Kalil AC, et al. Remdesivir for the treatment of COVID-19 - Final Report. N Engl J Med 2020; 5: 1813-26.

2. Li D, Wei T, Abbott CM, Harrich D. The unexpected roles of eukaryotic translation elongation factors in RNA virus replication and pathogenesis. Microbiol Mol Biol Rev 2013; 77: 253-66.

3. Papapanou M, Papoutsi E, Giannakas T, Katsaounou P. Plitidepsin. Mechanisms and clinical profile of a promising antiviral agent against COVID-19. J Pers Med 2021; 11(7): 668.

4. Rodon J, Muñoz-Basagoiti J, Perez-Zsolt D, Noguera-Julian M, Paredes R, Mateu L, et al. Identification of Plitidepsin as potent inhibitor of SARS-CoV-2-Induced cytopathic effect after a drug repurposing screen. Front Pharmacol 2021; 12: 646676.

5. https://clinicaltrials.gov/ct2/show/NCT04784559.

6. https://www.clinicaltrials.gov/ct2/show/NCT02100657?term= plitidepsin+in+multiple+myeloma\&draw $=2$ \&rank=1 .

7. White KM, Rosales R, Yildiz S, Kehrer T, Miorin L, Moreno E, et al. Plitidepsin has potent preclinical efficacy against SARS-CoV-2-2 by targeting the host protein eEF1A. Science 2021; 26: 926-31.

8. Jester BJ, Uyeki TM, Jernigan DB. Fifty years of influenza a(h3n2) following the pandemic of 1968. Am J Public Health 2020; 110: $669-76$. 